Journal of Business Management and
Economic Research
2019, 3 (12) DOI: $10.29226 /$ TR1001.2019.172
Journal Homepage: https://www.jobmer.org

\title{
DO SELF-AWARENESS AND SELF-REGULATION AFFECT KNOWLEDGE SHARING BEHAVIOR? EVIDENCE FROM KENYAN UNIVERSITIES: INTELLIGENCE UNMASKED
}

\section{Geoffrey Biwott ${ }^{*}$}

Department of Management Science, Moi University

gbiwott@gmail.com

* Corresponding author

\section{Patrick Limo}

Department of Marketing and Logistics, Moi University

\section{Loice Maru}

Department of Management Science, Moi University

\begin{abstract}
Universities have been identified as an accelerated centers of Knowledge sharing and changing behaviors of scholars as a critical asset for universities and this study paper deepens the understanding that Self-Awareness and Self-Regulation affect Knowledge Sharing Behavior among academic staff at universities in Kenya as an intelligence drive for modern universities in Kenya in harnessing knowledge to explore intelligence-sharing behaviors. Both concepts are individual responses as they understand and know one another even in Universities to strive for improved knowledge sharing between individuals. The study aimed at examining whether Self-Awareness and Self-Regulation affects Knowledge Sharing Behaviors among academic staff at universities in Kenya. Explanatory study was used to target a population of 6,423 and a sample size of 376 academic staff academic staff at Kenyan universities in Nairobi County was selected using simple random sampling. Data was collected using a structured questionnaire. The findings of the research revealed that self-awareness $(\beta=0.37$, $\mathrm{p}<0.05)$, and self-regulation $(\beta=0.11, \mathrm{p}<0.05)$, had a positive and significant effect on knowledge sharing behavior. Also R was $81 \%$ and R2 was $66 \%$. Concluding that emotional self-awareness and selfregulation are crucial to transforming universities in Kenya in achieving knowledge sharing behavior. Self-awareness and self-regulation in universities in Kenya have relatively been downplayed by government, respective institutions and scholars especially in harnessing knowledge yet the study contributes immensely that for leadership of universities in Kenya to drive, staff who must be selfaware and self-regulated in their emotions for free exchange of ideas and knowledge sharing.
\end{abstract}




\section{Introduction}

Knowledge sharing is documented in the scientific knowledge economy as a vital tool for organizations to achieve competitive advantage (Castro et al., 2013) and in ensuring long-term success. Knowledge sharing behavior is perceived to be one of the most essential knowledge management mechanisms in organizations. (Wang \& Hou, 2015). As such, processes should be put in place to facilitate and empower individuals and groups to enhance knowledge sharing behaviors and actions in organizational settings. A review of the literature on the behavior of individuals sharing knowledge indicates that the causes and factors involved in behaviors such as knowledge sharing are still considered to be difficult to comprehend in-depth and to analyze in greater detail (Holste \& Fields, 2010). It is therefore important to acknowledge what inspires individuals to share their knowledge as well as what prevents them from sharing it. Employees ' ability to share knowledge can be impacted not only by institutional factors but also by individual factors such as people's behaviors, motives, and attributes. Emotional intelligence can be one of the dimensions that can play a significant role in influencing their knowledge sharing actions.

Emotional intelligence has garnered a lot of research interest from scholars and practitioners respectively over the past two decades and has become one of the widely debated academic research themes in the fields of psychology, education, as well as management (Pradhan \& Nath, 2012). Emotional intelligence is known to be one of the most expedient individual differences distinctive features of institutional research systems (Brackett et al., 2013). According to (Benson, 2010) emotional intelligence encompasses the process of handling personal environmental and social changes by dealing with situations, addressing problems and making decisions quickly and objectively. (Iscan,2010) describe emotional intelligence as a mixture of desires, motives and fundamental values for handling the behaviors of individuals that are related to human connections and ascertaining the performance in the place of work. (Fayombo, 2012) found that emotional intelligence and skills are important to success in any institution. However, (Chopra \& Kanji, 2010) also posit that emotional intelligence could indeed help manage relationships, understand feelings, inspire and guide others. According to (Luu, 2014), emotional intelligence can trigger behavior and function as a bridge between cognition and behavior. This has to be seen that a high degree of emotional intelligence will aid not only to regulate our individual emotions but also to handle the emotions of others.

Darabi (2012) posits that emotional intelligence is the most fundamental human mechanism which involves the adaption to the environment. (Chin, 2010) has described emotional intelligence as a technique used by employees to identify both employee-related emotions, as well as emotional self- 
management, motivation, and social skills. (Petrides, 2009) identified fifteen dimensions of emotional intelligence and classified them into four variables: emotionality, self-control, sociability, and wellbeing. Emotional Intelligence appropriate intervention programs can inculcate a combination of diverse skills required for the same objective. Emotional intelligence therefore as becomes a vital factor to be considered in the institutional setup.

Knowledge distribution is the main function of universities (Ahmadi \& Ahmadi, 2012). Nevertheless, scientific discoveries are most often conducted in areas among disciplines, the division of university departments and silos research making interdisciplinary research difficult to institutionalize. Barriers and problems for knowledge sharing organizations are inevitable (Riege, 2005). A survey by Commission for University education revealed that the level of knowledge sharing among members of the respective organizations, including the academic staff was merely moderate (Mukhwana et al, 2018). Yet they are expert knowledge-intensive workers engaged in teaching, writing, and research and their education institutions generate value for knowledge using their intellectual assets and to share knowledge is part of their daily jobs and work activities. They create, manage disseminate and share knowledge with each other and with students. Therefore realizing the importance of knowledge sharing for academicians in promoting their learning and innovation would encourage them to practice it (Riege, 2005). Knowledge sharing in universities is experienced even though universities are knowledge service providers, many Kenyan universities are not utilizing knowledge to the fullest to improve their performance because the data, information, and knowledge available are not appropriately managed received and given when they could be efficiently shared and reused to generate new knowledge (Njoroge, 2017). Limited and very little empirical research investigating knowledge sharing behavior of academic staff at higher education is still scanty Delbridge, (2013). In addition, there has been considerable confusion about the connection between emotional intelligence outcomes, and many have failed to find significant link between emotional intelligence and knowledge sharing behavior. However, knowledge exchange processes which are not incorporated into staff and faculty day-to-day activities is a substantial duplication of effort.

\section{Review of Literature}

\subsection{Theoretical Framework}

The theory that underpinned the research is the theory of social exchange. The theory of social exchange, therefore, according to (Blau, 1964) is a widely applied theoretical foundation for the evaluation of individual knowledge-sharing behavior. According to this theory, individuals control 
their associations with other people on the basis of a self-interest analysis of both the benefits and costs of this kind of connection. Individuals try to maximize their economic advantages and reduce costs by sharing resources with others. These benefits do not need to be physical, since persons may engage with the expectation of mutual cooperation (Gouldner, 1960). In such exchanges people help others with the general belief of some future gains, such as the creation of desired resources via social mutual recognition. In order to optimize the resources made available, individuals should develop social interactions with others through sharing their knowledge. (Davenport \& Prusak, 1998) studied the behavior of knowledge sharing and presented some of the potential benefits which might regulate such behavior. Such benefits include potential proportionality, ranking, job security, and promotional opportunities. From this viewpoint, knowledge sharing will be positively influenced when a person intends to receive any future benefits by reciprocation (Cabrera \& Cabrera, 2005). Previous studies have indicated that factors contributing to the theory of social exchange have been effective in explaining the behavior of knowledge sharing between individuals. These include emotional cognition, interpersonal interaction and institutional contexts.

\subsection{Hypothesis Development}

\subsubsection{Link between Self-awareness and Knowledge Sharing Behavior}

Awareness of one's emotions, what causes them, and how we handle them is important in emotional intelligence (Carmeli, 2003). Emotions of leaders who are able to handle them rather than react to them and adapt to circumstances when they arise. An individual who is self-aware understands what influences their behavior, and the implications it has on others. The most common trademarks are selfdeprecating humor, realistic assessments of one's conduct, and a healthy dose of self-confidence. It is the willingness not to take yourself too seriously, while at the same time underestimating your value. Instead of responding to their emotional interactions their cognitive capacity to make better decisions thus reacting to emotions can damage relationships among staff. Self-aware leaders have a high awareness of the emotions of those around them. They are therefore able to get to the cause of strong emotional reactions of others (Goleman, 2001). Leaders not only should select the terms said, but also the emotions behind all the words. Individuals feel that they are being recognized when their emotions are acknowledged.

Each moment in the life of human beings is always within an experiential triangle of feelings, emotions, and actions. Thoughts that are powerful influence how a person feels and what a person performs. But then emotions are just as important, and so how a person feels affects his or her thoughts and actions. 
According to (Lennick \& Kiel, 2011) such as fear, anger, and optimism influence the thinking and thus drive everyone to actions and inactions. These are noticed by colleagues in any workplace and they affect work relationships. It is this self-awareness that will enable one to analyze one's thoughts, attitudes, feelings and actions, help to understand oneself better, make one act and react appropriately to situations. Such awareness which is to understand oneself, one's objectives, desires, emotions, behavior or being insightful to pick up what's going on inside oneself, is crucial in reducing one's personal stress and helping to create better relationships and a healthy working environment in any workplace. Based on the above, the study hypothesized:

H1: $\quad$ Self-awareness has no significant effect on knowledge sharing behavior

\subsubsection{Link between Self-Regulation and Knowledge Sharing Behavior}

(Zimmerman, 2013) says self-regulation is self-generated thoughts, feelings, and actions that are organized and cyclically tailored to the achievement of individual and institutional objectives. He states that self-regulation is a core human skill that gives us an evolutionary advantage and allows us to survive $\mathrm{He}$ argues that our self-regulation or lack of self-regulation is the foundation of the perception of an individual agency. He sees self-regulation as a relational system of interaction between social, behavioral and environmental factors. He pointed out that self-regulation is not a unique feature, skill or level of competence.

Self-regulation consists of an ability to think prior to acting, and also to suspend emotional judgment on occurrences. In addition to this, it involves having control over mood swings and impulses, and thus not allowing them to disrupt one's quality of life. Its trademarks include openness to change, integrity, reliability, and ease in accepting ambiguity. (Toyos, 2014), self-regulation includes cognitive, psychological, motivational and behavioral elements that provide a person with the ability to adjust his or her behaviors and goals in order to accomplish the desired outcomes in the context of dynamic environmental conditions. Schraw et al., (2016) modeled self-regulation in scientific education and categorized it into three elements, including perception, metacognition as well as motivation.

According to Carroll and Bahr (2013) self-regulation for learners and staff is seen as having the capacity to effectively set goals, agree on suitable strategies, schedule their time, coordinate and prioritize materials and data, flexibly change methods, track their teaching and learning by seeking input on their results, and make appropriate changes to anticipated learning practices. Several recent studies explicitly promote the implementation of self-regulation at the university level in a variety of contexts. Seraphin et al., (2012) discovered evidence that metacognitive reflection is a key driver of improvement 
in students ' analytical thinking patterns, resulting in enhanced critical thinking and scientific knowledge.

As determined by (Lin, Hung, \& Chen, 2009), knowledge sharing and self-regulation is one's confidence in an ability to provide knowledge that is valuable to others. In their research, knowledge sharing and self-regulation is a member's self-assessment and belief in his or her capacity and ability to respond to questions raised to other members as well as providing knowledge which is valuable and important to others. Through exchanging valuable knowledge, people feel much more confident about what they can do. (Bock \& Kim, 2002) suggest that self-regulation is regarded as a significant source of selfmotivation for sharing knowledge. Their discoveries disclose that the individual's judgment of his/her contribution to organization performance has a positive influence on knowledge sharing.

$H_{2:} \quad$ Self-regulation has no significant effect on knowledge sharing behavior

\section{Research Methodology}

This study emphasized on positivism while investigating the hypothesized causal explanation because the study is based on objectivity where objects exist independently (Elshafie, 2013). The study employed an explanatory research design built around testing the stated hypothesis (Hair et al., 2013). The target population comprised of 6423 academic staff from 14 chattered universities in Nairobi County main campuses only and not satellite campuses and constituents universities colleges. The sample size was 376 respondents while data was analyzed using linear regression.

\subsection{Reliability and validity of Measurements of Variables}

Study variables were operationalized and measured using already established study items from existing literature and where necessary, adaptations were made to fit the uniqueness of the study by making them context-specific. All the variables were measured using five-point likert scale. According to (Zikmund et al., 2013) likert scales with five-point or more were desirable than those that were shorter because they offered more variance, more sensitive and had a higher degree of measurement and information. Emotional intelligence independent variable (IV) was measured using the Wong and Law Emotional Intelligence Scale that comprised of 16 items (WLEIS; Law et al., 2004).. While Knowledge sharing behavior dependent variable (DV) was measured by the knowledge sharing scale by (Kankanhalli, Tan, \& Wei, 2005) which comprised of eight items was adopted.

From the results generated all variables had a Cronbach alpha of more than .70. Thus, the results met the required threshold for further analysis as presented in Table 1. The results depicted that the high 
factor loading scores were all above the minimum recommended value of 0.50 (Hair et al., 2015). The EFA extracted 1 factor with an Eigenvalue of 1 which is above the accepted value of 1 (Yong \& Pearce, 2013) and cumulative extracted variance above 50\%. Thus the items were appropriate to explain the variable. Moreover, from the Table 1, Bartlett's Test of Sphericity produced a significant Chi-Square $(\rho<0.05)$ and Kaiser - Meyer - Olkin measure of sampling adequacy was above the acceptable value of 0.50 (Field, 2005), showing that it was appropriate to subject data for factor analysis on this variable of knowledge sharing behavior (Leech et al., 2013).

Table 1 Reliability and Validity of Measurements of Variables

\begin{tabular}{|c|c|c|c|}
\hline $\mathrm{n}=337$ & Mean & Loadings & Cum \% \\
\hline $\begin{array}{l}\text { I accomplish my tasks through a good attitude and collaborative } \\
\text { knowledge with other colleagues }\end{array}$ & 3.960 & 0.894 & \\
\hline $\begin{array}{l}\text { Perceived behavioral control towards knowledge sharing } \\
\text { influence employees actual knowledge sharing behavior }\end{array}$ & 4.000 & 0.911 & \\
\hline I am willing to share my knowledge with my colleagues freely & 4.160 & 0.837 & \\
\hline $\begin{array}{l}\text { Attitude towards KS behavior influence employees intention to } \\
\text { share knowledge }\end{array}$ & 4.150 & 0.665 & \\
\hline When I learn new knowledge I share with my colleagues about it & 4.240 & 0.579 & \\
\hline $\begin{array}{l}\text { I seek my colleagues' knowledge sharing experience when I need } \\
\text { to learn something }\end{array}$ & 4.310 & 0.744 & \\
\hline $\begin{array}{l}\text { I utilize the available tools to share my knowledge with my } \\
\text { colleagues }\end{array}$ & 4.390 & 0.790 & \\
\hline I attend and contribute to different knowledge sharing activities & 4.360 & 0.912 & \\
\hline $\begin{array}{l}\text { KSB(Cronbach's Alpha=.865,KMO=.832, Bartlett's Test, Chi- } \\
\text { Square=1945.876**) }\end{array}$ & 4.197 & & 76.613 \\
\hline Expressing my emotions is not a problem for me & 3.590 & 0.812 & \\
\hline I often find it difficult to see things from another's perspective & 3.680 & 0.829 & \\
\hline On the whole, I'm a highly motivated person. & 3.950 & 0.895 & \\
\hline I usually find it difficult to regulate my emotions. & 3.700 & 0.660 & \\
\hline I have good control over my own emotions. & 3.880 & 0.677 & \\
\hline \multicolumn{4}{|l|}{ Self-awareness(Cronbach's Alpha=.0.831,KMO=.73,Bartlett's } \\
\hline Test, Chi-Square $=780.569^{* *}$ ) & 3.809 & & 60.832 \\
\hline Many times, I can't figure out my emotional feeling. & 3.090 & 0.692 & \\
\hline I feel that I have a number of good qualities. & 3.880 & 0.804 & \\
\hline I often find it difficult to stand up for my rights & 3.950 & 0.742 & \\
\hline I'm usually able to influence the way other people feel. & 4.140 & 0.730 & \\
\hline On the whole, I have a gloomy perspective on most things & 3.320 & 0.909 & \\
\hline \multicolumn{4}{|l|}{ Self-regulation(Cronbach's Alpha=.704,KMO=.689,Bartlett's } \\
\hline Test, Chi-Square $=371.044^{* *}$ ) & 3.674 & & 44.840 \\
\hline
\end{tabular}




\subsection{Analytical model}

Multiple linear regression model to analyze the effect of emotional intelligence on knowledge sharing behavior among academic staff in universities in Kenya. Regression of the outcome variable, which is the knowledge sharing behavior, with respect to the independent variables self-awareness and selfregulation was conducted. This produced a model for prediction. Hence multiple regression analysis was used to analyze data for this study. $\mathrm{R}^{2}$, the coefficient of determination provided a measure of the predictive ability of the model. The equation was:

$Y=\beta_{0}+\beta_{1} x_{1}+\beta_{2} x_{2}+\varepsilon$

Where;

$\mathrm{X}_{1:} \quad$ Represents emotional self-awareness

$\mathrm{X}_{2}: \quad$ Represents Self-regulation

Y: $\quad$ Represents the dependent variable (knowledge sharing behavior)

$\beta_{0} \quad$ Is a constant representing the Y-intercept

' $\beta 1^{\prime}$ to ' $\beta 2^{\prime}$ : $\quad$ Represent the effect of slope coefficients denoting the influence of the associated independent variables over the dependent variable.

$\varepsilon: \quad$ Represent the error term

\section{Results and Discussion}

This chapter presents the results of data analysis for the following;

\subsection{Demographic characteristics}

The researcher sought to establish the demographic information of the respondents paying close attention to their age, gender, length of job tenure, Level of education, Job scale in the university, and finally Leadership responsibility at the university in Table 2. The analysis of the background information of the respondents is critical in assessing confounders that might have a significant impact on the direction of the phenomenon under investigation. The findings put into account the age bracket of the respondents. In terms of the age of the employees $19.9 \%$ are below $30 \mathrm{yrs},(31.2 \%)$ between 31 to 40 years, $29.4 \%$ are in the 41 to 50 age brackets, $16.3 \%$ are between 51 to 60 years while $3.3 \%$ of the employees are over 60 years of age. From the results, $50.1 \%$ of the respondents were male, and $49.9 \%$ of them were female. The results indicate that there is an almost equal representation of both male and female employees though male employees comprise the majority. Since both male and female individuals are given a chance to share their knowledge for greater organizational achievement. Furthermore, $20.5 \%$ of the respondent's job tenure was 5 years or less, $33.5 \%$ was between $6-10$ years, $32.3 \%$ was between $11-15$ years, $9.5 \%$ was between $16-20$ years and $4.2 \%$ was more than 20 years. It is 
evident that the employees possess the requisite skills to perform their duties effectively. As such, the employees' job experience is part of the organizations' human capital.

The study revealed that the majority of the respondents (8\%) undergraduate Degree, followed by Master's Degree (34.1\%). Doctorate degrees were $47.8 \%$ while those with post-doctoral degrees were $10.1 \%$. It is evident that the employees possess the requisite skills to perform their duties effectively. As such, the employees' educational attainment is part of the organizations' human capital. For the job scale in the University $16.6 \%$ of the employees were graduate employees, $20.8 \%$ were tutorial fellow, $27 \%$ were lecturer and $24.6 \%$ were senior lecturer and $6.5 \%$ were professor. The implication is that the employees possess the required skills to give reliable information about the study problem. Finally, $25.8 \%$ had no leadership responsibility at the University, $27.9 \%$ of the employees were coordinators, $23.1 \%$ were head of department, $9.2 \%$ were deans and $4.5 \%$ were directors, $3.6 \%$ were principals, $1.8 \%$ were deputy principals, $1.5 \%$ were deputy vice-chancellors and $2.7 \%$ were chancellors.

Table 2: Demographic profile of respondents

\begin{tabular}{llcc}
\hline Variables & & Frequency & Percent \\
\hline Age bracket & Below 30yrs & 67 & 19.9 \\
& 31-40yrs & 105 & 31.2 \\
& $41-50$ yrs & 99 & 29.4 \\
& 51-60yrs & 55 & 16.3 \\
Above 60yrs & 11 & 3.3 \\
Tender & Total & 337 & 100 \\
& Male & 169 & 50.1 \\
Job tenure & Female & 168 & 49.9 \\
& Total & 337 & 100 \\
& 5yrs or less & 69 & 20.5 \\
& 6-10yrs & 113 & 33.5 \\
& 11-15yrs & 109 & 32.3 \\
Level of education & 16-20yrs & 32 & 9.5 \\
& More than 20yrs & 14 & 4.2 \\
& Total & 337 & 100 \\
& Undergraduate degree & 27 & 8 \\
& Master's degree & 115 & 34.1 \\
& Doctorate degree & 161 & 47.8 \\
& Post-doctoral degree & 34 & 10.1 \\
& Total & 337 & 100 \\
& Graduate assistant & 56 & 16.6 \\
& Tutorial fellow & 70 & 20.8 \\
& Lecturer & 91 & 27 \\
& Senior lecturer & 83 & 24.6 \\
& Associate professor & 22 & 6.5 \\
& Professor & 15 & 4.5 \\
& Total & 337 & 100
\end{tabular}




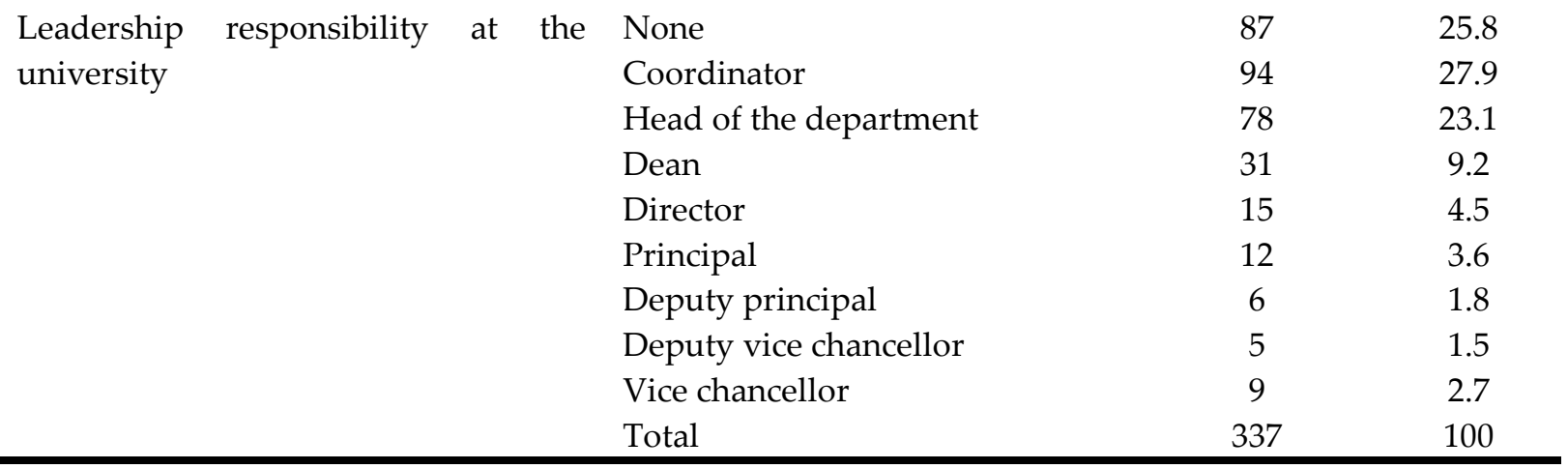

Source: Research Data (2019)

\subsection{Descriptive Statistics for Self-Awareness}

The first variable of the study was self-awareness. The results are presented in Table 3. The results indicate that most of the employees have no problem in expressing their emotions as indicated by $(\mathrm{M}=3.590, \mathrm{SD}=1.234)$. The results further shows that employees often find it difficult to see things from another employee's perspective was indicated by mean $(\mathrm{M}=3.680, \mathrm{SD}=1.107)$. The results shows that employees on whole regard themselves as highly motivated persons as indicated by the mean $(\mathrm{M}=$ $3.950, \mathrm{SD}=.999)$.

Further most employees usually find it difficult to regulate their emotions as shown by the results (M $=3.700, \mathrm{SD}=1.124)$. University Employees have good control of their own emotions as shown by the mean $(M=3.880, S D=1.114)$. Finally the overall mean of $(M=3.809, S D=0.689)$ shows that universities employees have the character of self-awareness. Further the result shows that the data experienced no skewness and kurtosis problems (-0.653 \& -0.043).

\section{Table 3: Descriptive Statistics for Self-awareness}

\begin{tabular}{|c|c|c|c|c|}
\hline$n=337$ & Mean & $\begin{array}{c}\text { Std. } \\
\text { Deviation }\end{array}$ & Skewness & Kurtosis \\
\hline Expressing my emotions is not a problem to me & 3.590 & 1.234 & -0.729 & -0.525 \\
\hline $\begin{array}{l}\text { I often find it difficult to see things from another's } \\
\text { perspective }\end{array}$ & 3.680 & 1.107 & -0.852 & 0.043 \\
\hline On the whole, I'm a highly motivated person. & 3.950 & 0.999 & -1.058 & 0.773 \\
\hline I usually find it difficult to regulate my emotions. & 3.700 & 1.124 & -0.674 & -0.420 \\
\hline I have good control of my own emotions. & 3.880 & 1.114 & -0.789 & -0.415 \\
\hline Self-awareness & 3.809 & 0.689 & -0.850 & 1.513 \\
\hline
\end{tabular}

Source: Research Data (2019) 


\subsection{Descriptive Statistics for Self-regulation}

The second variable of the study was Self-regulation. The results are presented in Table 4 . The results indicate that Many times most of the universities employees are not able figure out their emotional feeling as indicated by $(\mathrm{M}=3.090, \mathrm{SD}=1.321)$. The results further shows that most of universities employees feel that they have a number of good qualities as indicated by mean $(M=3.880, S D=1.015)$. The results shows that most of the employees time and again find it difficult to stand up for their rights as indicated by the mean $(\mathrm{M}=3.950, \mathrm{SD}=1.139)$.

Further most employees usually are able to influence the way other people feel as shown by the results $(\mathrm{M}=4.140, \mathrm{SD}=0.941)$. According to the results of the study Most of the University Employees have a gloomy perspective on most things as shown by the mean $(M=3.320, S D=1.302)$. Finally the overall mean of $(\mathrm{M}=3.674, \mathrm{SD}=0.751)$ shows that university employees have good knowledge on their own selfregulation. Further the result shows that the data experienced no skewness and kurtosis problems ($0.359 \&-0.226)$.

Table 4: Descriptive Statistics for Self-Regulation

\begin{tabular}{lcccc}
\hline $\mathrm{n}=337$ & \multicolumn{5}{c}{$\begin{array}{c}\text { Std. } \\
\text { Deviation }\end{array}$} & Skewness & Kurtosis \\
\hline Many times, I can't figure out my emotional feeling. & 3.090 & 1.321 & -0.248 & -1.110 \\
I feel that I have a number of good qualities. & 3.880 & 1.015 & -1.026 & 0.681 \\
I often find it difficult to stand up for my rights & 3.950 & 1.139 & -1.043 & 0.236 \\
I'm usually able to influence the way other people & & & & \\
feel. & 4.140 & 0.941 & -1.051 & 0.579 \\
$\begin{array}{l}\text { On the whole, I have a gloomy perspective on most } \\
\text { things }\end{array}$ & & & & \\
Self-regulation & 3.320 & 1.302 & -0.269 & -1.178 \\
\hline
\end{tabular}

Source: Research Data (2019)

\subsection{Tests for Regression Assumptions}

For the purposes of this study, normality tests were performed by utilizing the commonly used methods namely the Kolmogorov-Smirnov and Shapiro-Wilk tests (Ghasemi \& Zahediasi, 2012). The results in Table 5 confirmed that the normality of the data was not a problem because tests of K-S and S-W of all the variables were not significant. Hence, the data distribution in the study was reliable for multivariate analysis. Multicollinearity was tested by Variance Inflation Factor (VIF). The findings revealed that the VIF values for all the independent variables were below 10 and tolerance values of above 0.1 this means all the independent variables, had no multicollinearity. 
Table 5: Test for Normality and Multicollinearity

\begin{tabular}{lrrrrrr}
\hline & \multicolumn{3}{c}{ Kolmogorov-Smirnova } & \multicolumn{3}{c}{ Shapiro-Wilk } \\
& Statistic & Df & Sig. & Statistic & df & Sig. \\
\hline Unstandardized Residual & 0.023 & 337 & $.200^{*}$ & 0.998 & 337 & 0.992 \\
Standardized Residual & 0.023 & 337 & $.200^{*}$ & 0.998 & 337 & 0.992 \\
Studentized Residual & 0.023 & 337 & $.200^{*}$ & 0.998 & 337 & 0.99 \\
\hline \multicolumn{7}{c}{ Multicollinearity Statistics } \\
\hline Self-awareness & \multicolumn{5}{c}{ Tolerance } \\
Self-regulation & \multicolumn{7}{c}{0.591} & VIF & 1.693 \\
\hline
\end{tabular}

* This is a lower bound of the true significance.

a Lilliefors Significance Correction

Source: Research Data (2019)

\subsection{Correlation analysis}

The resultant correlations were indicated by the prefix ' $r$ ' where the degree of correlation was expressed by a value of the coefficient (Katz 2006). From the results in table 6, there is a positive and significant correlation between the independent variables and knowledge sharing behavior. Particularly, the correlation results showed that self-awareness has a positive and significant relationship with knowledge sharing behavior $(r=.666, \rho<0.01)$. Self-regulation positively and statistically significantly correlates with knowledge sharing behavior $(r=.533, \rho<0.01)$.

Table 6: Pearson correlation coefficient of the study variable

\begin{tabular}{lccc}
\hline & KSB & SA & SR \\
\hline Knowledge Sharing Behavior & 1 & & \\
Self-Awareness & $.666^{* *}$ & 1 & \\
Self-Regulation & $.533^{* *}$ & $.502^{* *}$ & 1 \\
\hline
\end{tabular}

** Correlation is significant at the 0.01 level (2-tailed).

Source: Research Data (2019)

$\begin{array}{lll}K S B & = & \text { knowledge sharing behavior } \\ S A & = & \text { self-awareness } \\ S R & = & \text { self-regulation }\end{array}$

\subsection{Test of hypothesis}

Hypotheses were proposed to examine the effect of self-awareness and self-regulation on knowledge sharing behavior tests to ascertain the effects of relationship. A multiple linear regression analysis was performed to calculate the coefficients of independent variables with knowledge sharing behavior. The combined prediction of all the variables accounted for approximately $66 \%$ of the total variation in 
knowledge sharing behavior $\left(R=.81, R^{2}=.66\right)$. The regression model showed that joint prediction of all the independent variables as depicted in Table 7 was statistically significant $(F=127.88, \rho=.000)$. Thus, the model was fit to predict knowledge sharing behavior using self-awareness and self-regulation.

Hypothesis ( $\mathrm{H}_{1}$ :) stated no significant effect of self-awareness on knowledge sharing behavior among academic staff in Kenyan universities. However, the findings in Table 7 showed that self-awareness has a positive and significant effect on knowledge sharing behavior $(\beta=0.37, \mathrm{p}<.05)$. This implies that there is a probability of 0.347 that knowledge sharing behavior would increase with increase in selfawareness. More findings revealed that the effect on knowledge sharing behavior is attributed to selfawareness by over 9 times $(\mathrm{t}=9.37)$ more compared to the effect attributed to the standard error associated with it. (Goleman, 2001) supported this indicating that employees who are aware of their emotions and able to manage them, (rather than to react to them) and adequately respond to situations and able to engage their thinking capacity for better decisions. Reacting to emotions can damage relationships among staff. Self-aware employees have a high awareness of the emotions of those around them. They are therefore able to get to the cause of strong emotional reactions of others. Employees should not only pick words being spoken but also emotions behind the words. People feel they are being heard when their emotions are acknowledged.

Hypothesis $\left(\mathrm{H}_{2}\right.$ :) stated no significant effect of self-regulation on knowledge sharing behavior among academic staff in Kenyan universities. However, the findings showed that self-regulation has a positive and significant effect on knowledge sharing behavior $(\beta=0.11, p<0.05)$. This implies a probability of 0.11 that knowledge sharing behavior would increase with increase in self-regulation. More findings revealed that the effect on knowledge sharing behavior is attributed to self-regulation by over 2 times $(\mathrm{t}=2.558)$ more compared to the effect attributed to the standard error associated with it. This supported by (Lin et al., 2009), as they determined that knowledge sharing and self-regulation is one's confidence in an ability to provide knowledge that is valuable to others. Through sharing useful knowledge, people feel more confident in what they can do. 
Table 7: Regression Coefficient of Study Variables

\begin{tabular}{lccccc}
\hline & \multicolumn{2}{c}{ Unstandardized } & \multicolumn{3}{c}{ Standardized Coefficients } \\
& B & Std. Error & Beta & T & Sig. \\
\hline (Constant) & 0.37 & 0.16 & & 2.39 & 0.02 \\
Self-Awareness & 0.36 & 0.04 & 0.37 & 9.37 & 0.00 \\
Self-Regulation & 0.10 & 0.04 & 0.11 & 2.58 & 0.01 \\
\hline Summary Statistics & & & & & \\
\hline$R$ & 0.81 & & & & \\
$R$ Square & 0.66 & & & & \\
Adjusted R Square & 0.65 & & & & \\
Std. Error of the Estimate & 0.43 & & & & \\
Change Statistics & & & & & \\
F Change & 127.88 & & & & \\
df1 & 5.00 & & & & \\
df2 & 331.00 & & & & \\
Sig. F Change & 0.00 & & & & \\
Durbin-Watson & 1.84 & & & & \\
\hline
\end{tabular}

a Dependent Variable: KSB

\section{Conclusion}

The findings concluded that self-awareness results lead to improved employee knowledge sharing. Workers who had strong self-awareness were realistic in whatever choices they make and in doing their work. From the findings the aspect of self-awareness serving as a basis for self-reflection had a marginal correlation with knowledge sharing behavior, Self-aware people typically finding time to selfevaluate had a significant effect on performance and knowledge sharing, and Universities management in Kenya needs to find a way of encouraging its employees to think things over rather than react impulsively.

The findings also concluded that improving employee's self-regulation abilities result in improved employee performance and knowledge sharing since they are in control of their emotions by ensuring these emotions are effectively managed to avoid it affecting their work and persons they relate at work.

\section{Recommendations}

The study recommended that Universities in Kenya needs to help its staff to improve on their selfawareness if they need improved employee knowledge sharing. The universities need to focus on developing workers to have strong self-awareness for realistic choices at work. Self-aware workers should be encouraged to refrain from expressing the anyhow they like, being over self-critical or naively hopeful in doing their work. Self-awareness should serve as a tendency for self-reflection and 
thoughtfulness. Self-awareness needs to be encouraged and promoted so that the employees are in a better position to evaluate their actions and make very informed decisions.

The study further recommends to Universities in Kenya that they should optimize staff's self-regulation abilities such as how an employee can figure out their emotional feeling, which then leads to the attainment of overall organizational performance. Emotional self-regulation needs to be managed by management leadership to endeavor employees to be in control of their emotions and ensure these emotions are effectively managed to avoid it affecting their work to improve output and work relationships. Transparency needs to be highly promoted so that staff can live their values, and where necessary they can openly admit mistakes and fault which can be corrected for improved later knowledge sharing and performances. Universities in Kenya need to develop and recognize employees who constantly struggle to achieve something and ensure high standards at workplace through proper self-regulation abilities. Achievement-oriented leaders are recommended because they are interested in continually learning and teaching, wants to do things better and this is good for the attainment of general organizational objective of better performance.

\section{References}

Ahmadi, A., \& Ahmadi, F. (2012). Knowledge Management in Iranian University (Case Study Shushtar University). Interdisciplinary Journal of Contemporary Research in Business, 4(5), 653-667.

Arakelian, A., Maymand, M. M., \& Hosseini, M. H. (2013). Study of the relationship between Emotional Intelligence (EI) and Knowledge Sharing (KS). European Journal of Business and Management, 5(32), 203-216.

Benson, G., Ploeg, J., \& Brown, B. (2010). A cross-sectional study of emotional intelligence in baccalaureate nursing students. Nurse Education Today, 30(1), 49-53.

Blau, P. (1964). Power and exchange in social life. NY: John Wiley \& Sons.

Bock, G. W., \& Kim, Y.-G. (2002). Breaking the myths of rewards: An exploratory study of attitudes about knowledge sharing. Information Resources Management Journal (IRMJ), 15(2), 14-21.

Brackett, M. A., Rivers, S. E., \& Salovey, P. (2011). Emotional intelligence: Implications for personal, social, academic, and workplace success. Social and Personality Psychology Compass, 5(1), 88-103.

Cabrera, E. F., \& Cabrera, A. (2005). Fostering knowledge sharing through people management practices. The international journal of human resource management, 16(5), 720-735.

Carmeli, A. (2003). The relationship between emotional intelligence and work attitudes, behavior and outcomes: An examination among senior managers. Journal of managerial Psychology, 18(8), 788813.

Castro, G. M.-d., Delgado-Verde, M., Amores-Salvadó, J., \& Navas-López, J. E. (2013). Linking human, technological, and relational assets to technological innovation: exploring a new approach. Knowledge Management Research \& Practice, 11(2), 123-132.

Chin, W. W. (2010). How to write up and report PLS analyses Handbook of partial least squares (pp. 655690): Springer.

Chopra, P. K., \& Kanji, G. K. (2010). Emotional intelligence: A catalyst for inspirational leadership and management excellence. Total quality management, 21(10), 971-1004. 
Davenport, T. H., \& Prusak, L. (1998). Working knowledge: How organizations manage what they know: Harvard Business Press.

Effeney, G., Carroll, A., \& Bahr, N. (2013). Self-Regulated Learning: Key strategies and their sources in a sample of adolescent males. Australian Journal of Educational \& Developmental Psychology, 13.

Elshafie, M. (2013). Research Paradigms: The Novice Researcher's Nightmare. Arab World English Journal, 4(2).

Fayombo, G. A. (2012). Emotional Intelligence and Gender as Predictors of Academic Achievement among Some University Students in Barbados. International Journal of Higher Education, 1(1), $102-111$.

Field, A. (2005). Discovering statistics using SPSS (2. baskı). Londra: Sage Pub.

Fullwood, R., Rowley, J., \& Delbridge, R. (2013). Knowledge sharing amongst academics in UK universities. Journal of knowledge management, 17(1), 123-136.

Ghasemi, A., \& Zahediasl, S. (2012). Normality tests for statistical analysis: a guide for non-statisticians. International journal of endocrinology and metabolism, 10(2), 486.

Goleman, D. (2001). An EI-based theory of performance. The emotionally intelligent workplace: How to select for, measure, and improve emotional intelligence in individuals, groups, and organizations, 1, 2744.

Gouldner, A. W. (1960). The norm of reciprocity: A preliminary statement. American sociological review, 161-178.

Gulluce, A. C., \& Iscan, O. F. (2010). The Relationship between Occupational Burnout and Emotional Intelligence. ESKISEHIR OSMANGAZI UNIVERSITESI IIBF DERGISI-ESKISEHIR OSMANGAZI UNIVERSITY JOURNAL OF ECONOMICS AND ADMINISTRATIVE SCIENCES, $5(2), 7-29$.

Hair Jr, J. F., Wolfinbarger, M., Money, A. H., Samouel, P., \& Page, M. J. (2015). Essentials of business research methods: Routledge.

Holste, J. S., \& Fields, D. (2010). Trust and tacit knowledge sharing and use. Journal of knowledge management, 14(1), 128-140.

Kankanhalli, A., Tan, B. C., \& Wei, K.-K. (2005). Contributing knowledge to electronic knowledge repositories: An empirical investigation. MIS quarterly, 29(1).

Katz, S., \& Sharpe, E. (2006). Notes on certain $(0,2)$ correlation functions. Communications in mathematical physics, 262(3), 611-644.

Law, K. S., Wong, C.-S., \& Song, L. J. (2004). The construct and criterion validity of emotional intelligence and its potential utility for management studies. Journal of applied Psychology, 89(3), 483.

Leech, N., Barrett, K., \& Morgan, G. A. (2013). SPSS for intermediate statistics: Use and interpretation: Routledge.

Lennick, D., \& Kiel, F. (2011). Moral Intelligence 2.0: Enhancing Business Performance and Leadership Success in Turbulent Times, Portable Documents: Pearson Prentice Hall.

Lin, M.-J. J., Hung, S.-W., \& Chen, C.-J. (2009). Fostering the determinants of knowledge sharing in professional virtual communities. Computers in Human Behavior, 25(4), 929-939.

Luu, T. (2014). Knowledge sharing and competitive intelligence. Marketing Intelligence \& Planning, 32(3), 269-292.

Mukhwana, E., Oure, S., Too, J., \& Some, D. (2016). State of Postgraduate Research Training in Kenya. Commission for University Education: Discussion Paper 02. Nairobi, Kenya.

Njoroge, C. W. (2017). Factors Influencing Effective Strategy Implementation in Sameer Africa Limited. United States International University-Africa.

Petrides, K. (2009). Trait emotional intelligence questionnaire (TEIQue). URL: http://www. eiconsortium. org/measures/teique. html [accessed on 1st October 2011]. 
Pradhan, R. K., \& Nath, P. (2012). Perception of entrepreneurial orientation and emotional intelligence: A study on India's future techno-managers. Global Business Review, 13(1), 89-108.

Riege, A. (2005). Three-dozen knowledge-sharing barriers managers must consider. Journal of knowledge management, 9(3), 18-35.

Schraw, G., Crippen, K. J., \& Hartley, K. (2006). Promoting self-regulation in science education: Metacognition as part of a broader perspective on learning. Research in science education, 36(12), 111-139.

Seraphin, K. D., Philippoff, J., Kaupp, L., \& Vallin, L. M. (2012). Metacognition as means to increase the effectiveness of inquiry-based science education. Science Education International, 23(4), 366-382.

Toyos, F. T. D. (2014). University Teachers' Views on (Personalized) Learning and Self-Regulation: A Grounded-Theory Analysis. Paper presented at the Forum Qualitative Sozialforschung/Forum: Qualitative Social Research.

Wang, W.-T., \& Hou, Y.-P. (2015). Motivations of employees' knowledge sharing behaviors: A selfdetermination perspective. Information and Organization, 25(1), 1-26.

Zikmund, W., Babin, B., Carr, J., \& Griffin, M. (2013). Business research methods (ninth edit). Erin Joyner, Cangage Learning.

Zimmerman, B. J. (2013). Theories of self-regulated learning and academic achievement: An overview and analysis Self-regulated learning and academic achievement (pp. 10-45): Routledge. 